\title{
RANCANG BANGUN PROTOTYPE ROBOT LENGAN MENGGUNAKAN FLEX SENSOR DAN ACCELEROMETER SENSOR PADA LAB MIKROKONTROLER STMIK MUSIRAWAS
}

\author{
M. Agus Syamsul Arifin \\ masa@stmik.muralinggau.ac.id \\ STMIK Musirawas Lubuklinggau
}

\begin{abstract}
Abstrak
Perkembangan teknologi khususnya dunia Robotika yang pesat membawa dunia menuju sebuah zaman dimana pada beberapa aspek pekerjaan mulai digantikan dengan robot. Dalam berbagai kasus robot menjadi pilihan utama karena dapat mengurangi cost pengeluaran bagi perusahaan, selain itu hasil pekerjaan yang dilakukan oleh robot lebih presisi dan lebih detail dengan waktu pengerjaan yang lebih singkat dibandingkan dengan menggunakan tenaga manusia. Beberapa kasus kombinasi Manusia dan Robot menjadi solusi untuk permasalahan yang khusus yagn tidak bias dilakukan hanya dengan menggunakan robot saja. Penelitian ini membangun sebuah prototype robot lengan yang di kendalikan menggunakan Flex sensor dan Accelerometer sensor untuk menggerakkan lengan dan menggunakan smartphone dan Bluetooth untuk mengendalikan arah laju robot. Kontrol manusia dilakukan untuk lebih fleksibel dalam menyelesaikan pekerjaan dimana akan sangat sulit jika hanya mengandalkan robot saja disini manusia mengendalikan robot untuk memindahkan barang di tempat yang belum ditentukan titik pemindahannya. Pengedalian menggunakan flex sensor dan accelerometer mempermudah pengendalian lengan robot agar lebih presisi dalam penerapannya.
\end{abstract}

Kata kunci: Flex Sensor, Accelerometer Sensor, Mikrokontroler, Arduino

\section{Pendahuluan}

Perkembangan dunia teknologi khususnya dunia Robotika yang pesat membawa dunia menuju sebuah zaman dimana pada beberapa aspek pekerjaan mulai digantikan dengan robot. Dalam berbagai kasus robot menjadi pilihan utama karena dapat mengurangi cost pengeluaran bagi perusahaan selain itu hasil pekerjaan yang dilakukan oleh robot lebih presisi dan lebih detail dengan waktu pengerjaan yang lebih singkat dibandingkan dengan menggunakan tenaga manusia.

Di beberapa kasus kombinasi Manusia dan Robot menjadi solusi untuk permasalahan yang khusus seperti dalam kasus penjinakkan bom, memindahkan barang - barang dengan beban yang berat di butuhkan control manusia untuk lebih fleksibel dalam menyelesaikan pekerjaan dimana akan sangat sulit jika hanya mengandalkan robot saja disini manusia mengendalikan robot untuk memindahkan barang di tempat yang belum ditentukan titik pemindahannya, sedangkan robot harus ditentukan dahulu titik pemindahan barang tersebut. Begitu juga ketika menjinakkan bom dimana setiap kasus memiliki rangkaian elektronika yang berbeda - beda. Pada penelitian ini akan membangun sebuah prototype robot yang di kendalikan untuk dapat memindahkan barang dengan menggunakan flex sensor dan accelerometer sensor untuk kendali lengannya lalu Bluetooth untuk mengendalikan arah robot ketika berjalan semua system dip roses menggunakan mikrokontroler.

Mikrokontroler adalah suatu system yang mengandung masukan/keluaran, memori, dan prosessor yang digunakan pada produk elektronika. Arduino adalah jenis papan yang berisi mikrokontroler, dengan kata lain arduino adalah sebuah papan mikrokontroler [1]. Penelitian ini menggunakan arduino karena kemudahan yang di berikan dan kehandalan system yang sudah teruji. Untuk menggerakkan penjepit robot menggunakan flex sensor, Flex sensor merupakan sebuah sensor fleksibel yang memiliki panjang 4,5 inch dan berfungsi untuk mendeteksi suatu kelengkungan. Untuk menggunakan flex sensor kita membutuhkan rangkaian pembagi tegangan [2]. Sistem kendali lengan menggunakan Accelerometer sensor untuk mengendalikan arah lengan agar sesuai dengan yang diinginkan dan lebih presisi. Accelerometer adalah sensor percepatan, dengan keluaran berupa 
tegangan per navigasi bumi (Mv/g). Accelerometer mengukur percepatan akibat gerakan benda yang melekat padanya pada saat diam percepatan suatu benda nol (tegangan Accelerometer relative positif dibandingkan dengan offsetnya) dan kemudian negative (tegangan Accelerometer relatif negatif dibandingkan dengan offsetnya), sehingga pada saat berhenti percepatan kembali nol. Pada gerak tersebut, percepatan suatu benda bertambah kemudian berkurang dan akhirnya menjadi nol saat berhenti [3].

\section{Metode}

Metode yang di gunakan pada penelitian ini adalah rapid prototyping. Alur metode yang di gunakan dapat dilihat pada gambar 1

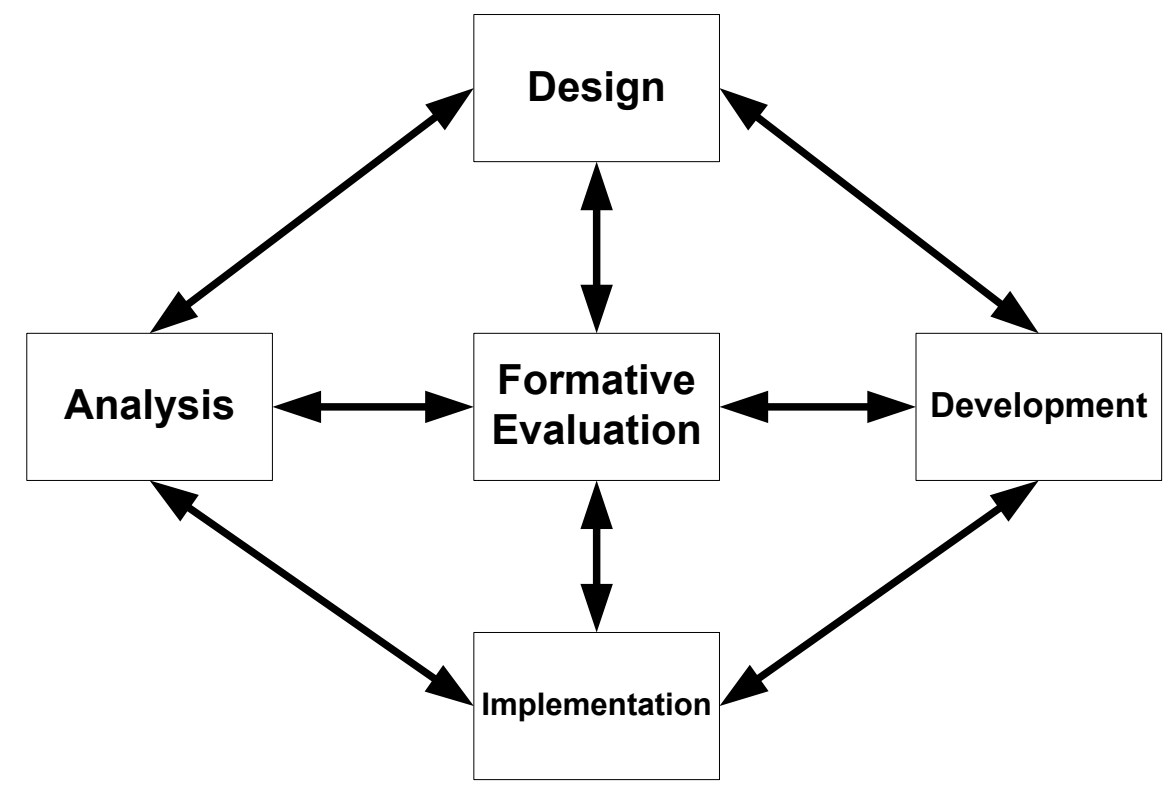

Gambar 1. Model rapid prototyping

Penjelasan alur penelitian menggunakan Rapid Prototyping Model :

1. Analisis dilakukan untuk menentukan komponen apa saja yang di butuhkan untuk membangun system robot lengan ini.

2. Kemudian langkah selanjutnya adalah melakukan desain pada tahapan ini yang dilakukan adalah merancang system input, proses dan output yang akan di gunakan dan dihasilkan pada system.

3. Development akan di lakukan apabila system yang sudah didisain tersebut sesuai dengan yang di inginkan sehingga proses development dapat di lakukan.

4. Proses implementation dapat dilakukan apabila system yang di buat sudah dapat berjalan dengan baik baik control lengan menggunakan accelerometer sensor dan control capit robot yang dikendalikan menggunakan flex sensor.

5. Formative Evaluation bertujuan untuk menentukan apa yang harus ditingkatkan dari sistem yang di bangun agar sistem yang dibangun lebih efektif dan efisien

Sistem pengandalian robot lengan ini di bagi menjadi dua yaitu system gerak untuk mendekati objek dikendalikan menggunakan Bluetooth melalui smartphone dan system pemindah benda yang berupa lengan yang di kendalikan menggunakan flex sensor dan accelerometer sensor. 
ILKOM Jurnal Ilmiah Volume 9 Nomor 3 Desember 2017

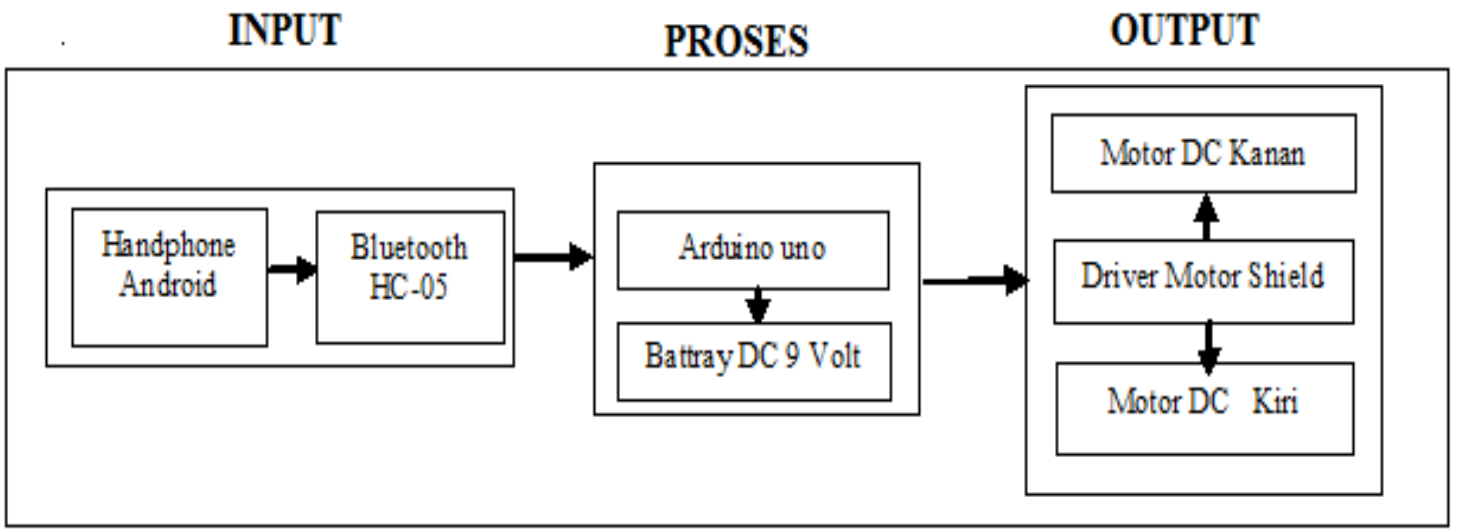

Gambar 2. Sistem kendali arah robot menggunakan Bluetooth

Handphone android akan di koneksikan ke bluetooth untuk dapat mengirimkan perintah ke arduino guna menggerakkan motor DC robot sehingga Robot lengan ini dapat bergerak sesuai keinginan. Perintah dari handphone adroid akan di proses pada arduino yang terdapat pada perangkat robot.

\section{INPUT \\ PROSES \\ OUTPUT}

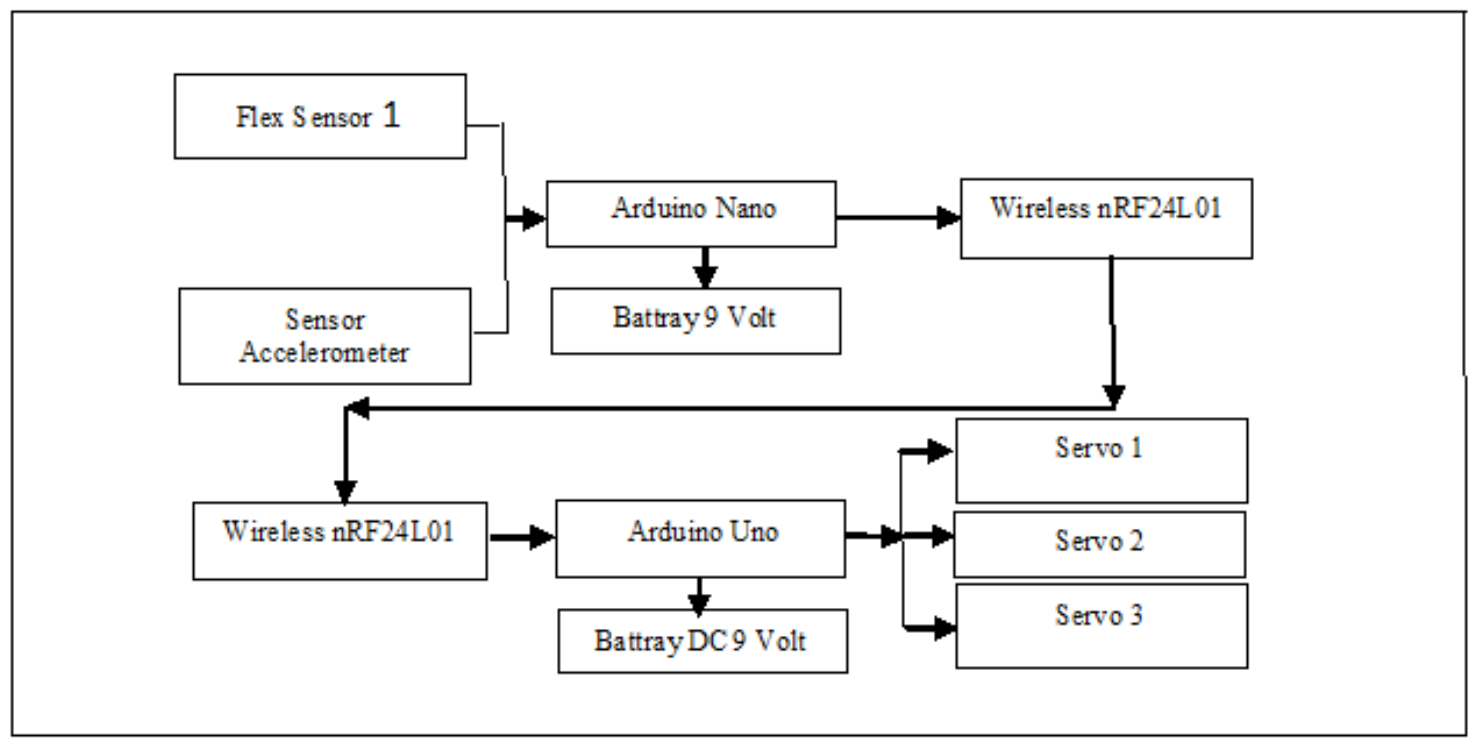

Gambar 3. Diagram blok Lengan Robot

Dari sisi pengendali robot input gerak lengan akan di lakukan dengan flex sensor dan accelerometer sensor yang akan menggerakkan motor servo pada sisi perangkat robot yang akan di proses di arduino pada system perangkat pengendali dan akan di kirimkan ke Robot menggunakan wireless nRF24I01 sebagai media transmisinya.

\section{Hasil dan Pembahasan}

\subsection{Hasil}

Pada bagian ini akan di jelaskan hasil dan system rangkaian yang digunakan untuk membangun prototype robot lengan baik dari system pengendali maupun system pada perangkat robot.

Tabel 1. Hasil Pengujian Kendali Robot

\begin{tabular}{|l|l|l|c|c|}
\hline \multirow{2}{*}{ No } & \multicolumn{2}{|c|}{ Pengujian } & \multicolumn{1}{|c|}{ Proses dan Output } & \multicolumn{2}{|c|}{ Hasil } \\
\cline { 3 - 5 } & Motor DC & $\begin{array}{l}\text { Robot bergerak maju, mundur, } \\
\text { dan belok kiri, kanan. }\end{array}$ & $\sqrt{ }$ & \\
\hline 1 & & \multicolumn{2}{|c|}{ Tidak } \\
\hline
\end{tabular}


ILKOM Jurnal Ilmiah Volume 9 Nomor 3 Desember 2017

\begin{tabular}{|c|c|c|c|}
\hline 2 & Bluetooth HC-05 & $\begin{array}{l}\text { Motor DC bisa dikontrol jarak } \\
\text { jauh menggunakan android } \\
\text { dengan koneksi Bluetooth } H C-05 \text {. }\end{array}$ & $\sqrt{ }$ \\
\hline 3 & $\begin{array}{l}\text { Sensor } \\
\text { Accelerometer }\end{array}$ & $\begin{array}{l}\text { Lengan robot bisa bergerak } \\
\text { mengikuti gerak Accelerometer } \\
\text { melalui } W \text { ireless } n R F 24 L 01 \text {. }\end{array}$ & $\sqrt{ }$ \\
\hline 4 & Flex Sensor & $\begin{array}{l}\text { Jari-jari pada servo } 4 \text { lengan robot } \\
\text { bergerak sesuai kelengkungan } \\
\text { Flex Sensor. }\end{array}$ & $\sqrt{ }$ \\
\hline 5 & Wireless $n R F 24 L 01$ & $\begin{array}{l}\text { Wireless } n R F 24 L 01 \text { mengirim } \\
\text { perintah dari Flex Sensor dan } \\
\text { Accelerometer } \\
\text { menggerakan lengan robot yang } \\
\text { diproses pada arduino. }\end{array}$ & $\sqrt{ }$ \\
\hline
\end{tabular}

System penggerak arah robot akan bekerja setelah menerima perintah dari Handphone Android melalui media transmisi Bluetooth yang di proses di arduino yang terdapat pada Robot. Servo pada jari - jari robot akan bergerak sesuai dengan lengkukan yang di terapkan pada Flex sensor begitu juga lengan robot akan bergerak sesuai arah dari Accelerometer sensor, perintah - perintah ini akan di proses menggunakan perangkat Arduino yang ada pada sarung tangan pengendali dan akan di kirimkan ke robot menggunakan media transmisi wireless pada modul nRF24L01 dan akan diterima pada perangkat robot.

Tabel 2. Hasil Pengukuran Motor DC

\begin{tabular}{|c|c|}
\hline Motor Tidak Aktif & Motor Aktif \\
\hline 0,2 VDC & 11,80 VDC \\
\hline 0,2 VDC & 11,72 VDC \\
\hline 0,1 VDC & 11,67 VDC \\
\hline
\end{tabular}

Pada hasil pengukuran motor DC akan aktif ketika mendapatkan tegangan minimal 11,67 V dalam arus DC.

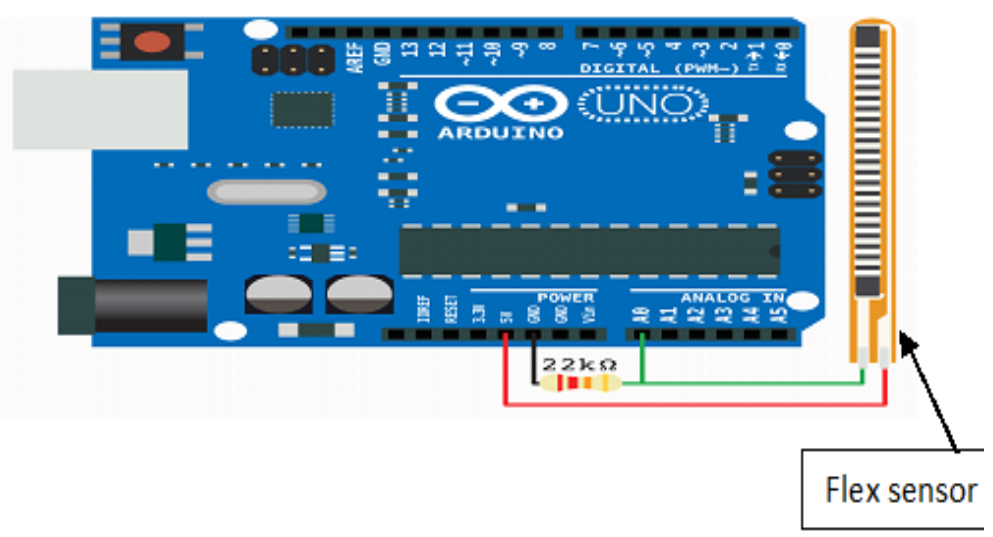

Gambar 4. Rangkaian Flex sensor

Flex sensor pada kedua outputnya adalah berupa resistansi berkisar $10-22 \mathrm{~K}$ ohm, yang berubah ketika flex sensor itu ditekuk. Semakin ditekuk, semakin besar nilai resistansinya nilai resistensi ini akan menjadi sinyal informasi yang akan di proses oleh arduino. 


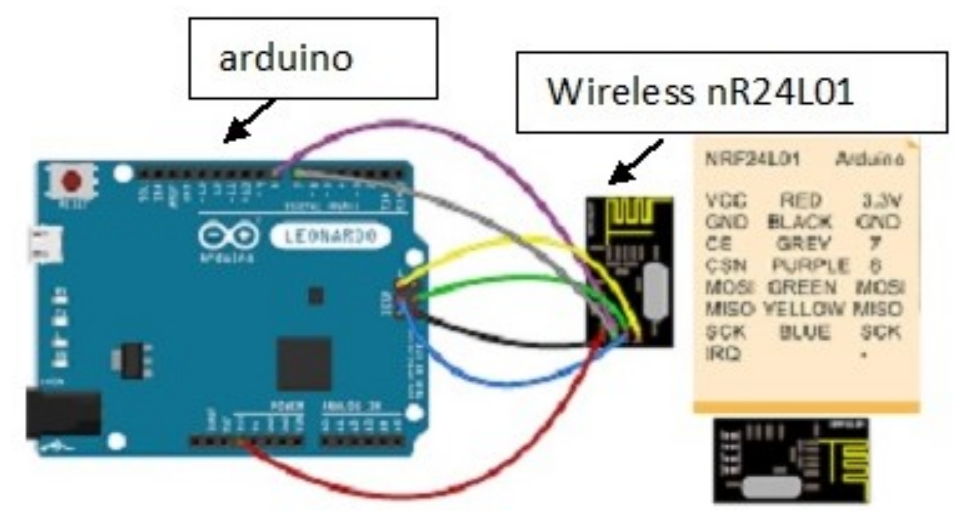

Gambar 5. Rangkaian Penghubung antara robot dengan sensor kendali (Flex sensor dan Accelerometer Sensor)

Untuk menghubungkan antara lengan robot dan perangkat pengendali dibutuhkan modul Wireless nR24L01 informasi yang akan di kirim maupun yang sudah diterima kan diproses oleh arduino.

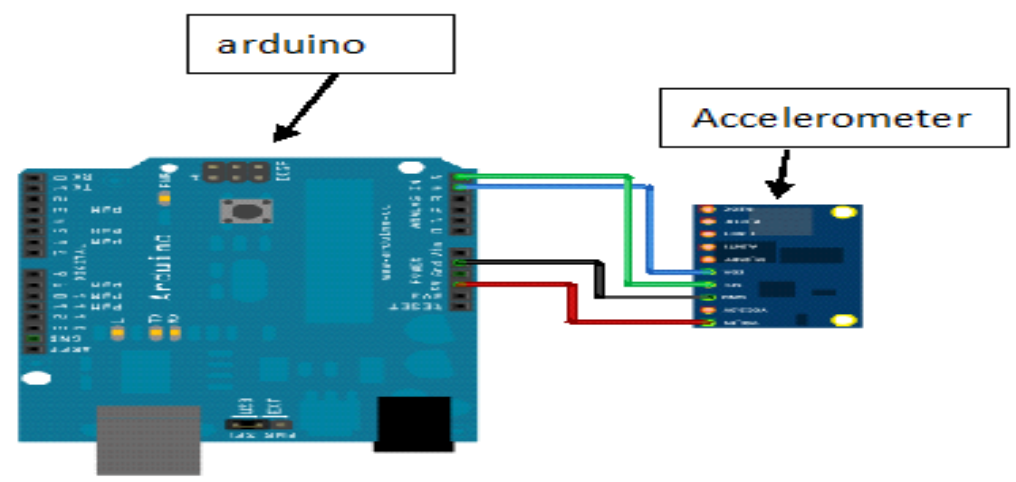

Gambar 6. Rangkaian Sensor Accelerometer sebagai pengendali arah lengan robot

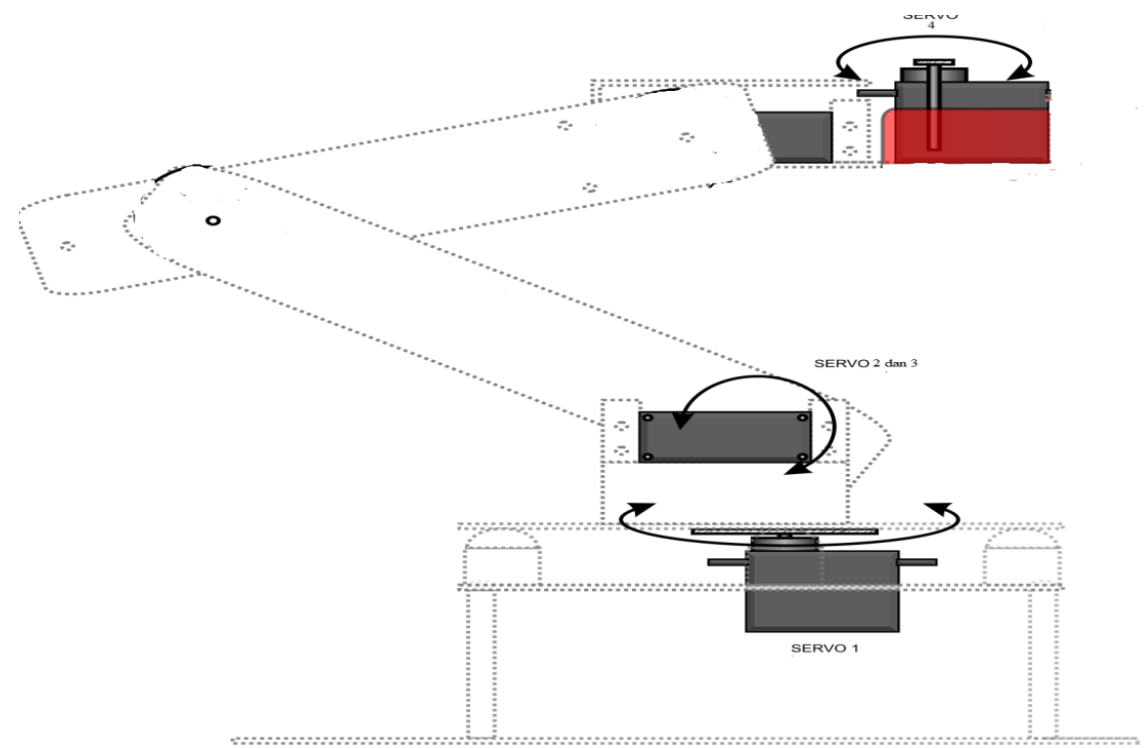

Gambar 7. Sistem Gerak Lengan Robot

Sensor accelerometer dapat mendeteksi kemiringan sehingga pada system ini sensor accelerometer di gunakan untuk mengendalikan arah lengan robot. Sinyal informasi dari sensor accelerometer ini akan di proses pada arduino dan pada system ini akan di kirimkan menggunakan Wireless nR24L01 ke perangkat robot. 


\subsection{Pembahasan}

Untuk mengendalikan jari penjepit robot flex sensor di letakkan seperti pada gambar lalu di hubungkan ke arduino nano yang berguna untuk memproses data. Data tersebut dikirimkan menggunakan media transmisi wireless dengan menggunakan modul wireless NR24L01 agar terkoneksi ke robot.

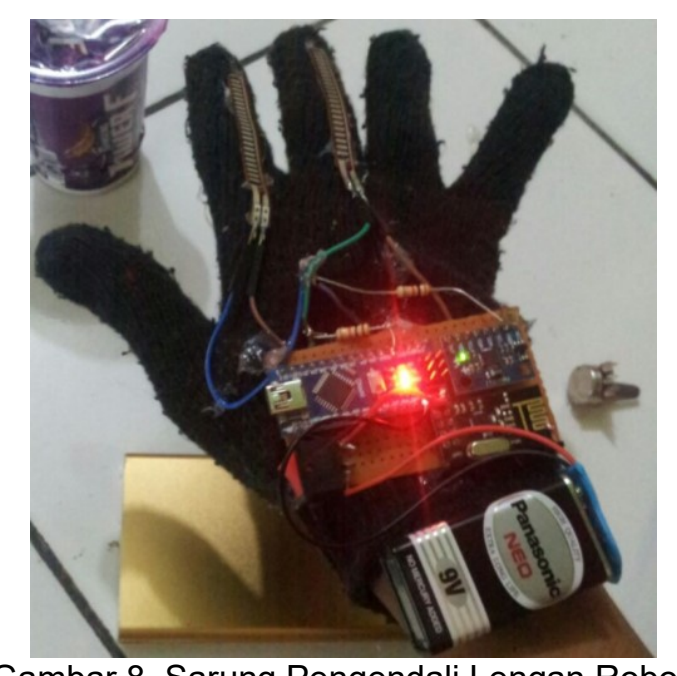

Gambar 8. Sarung Pengendali Lengan Robot

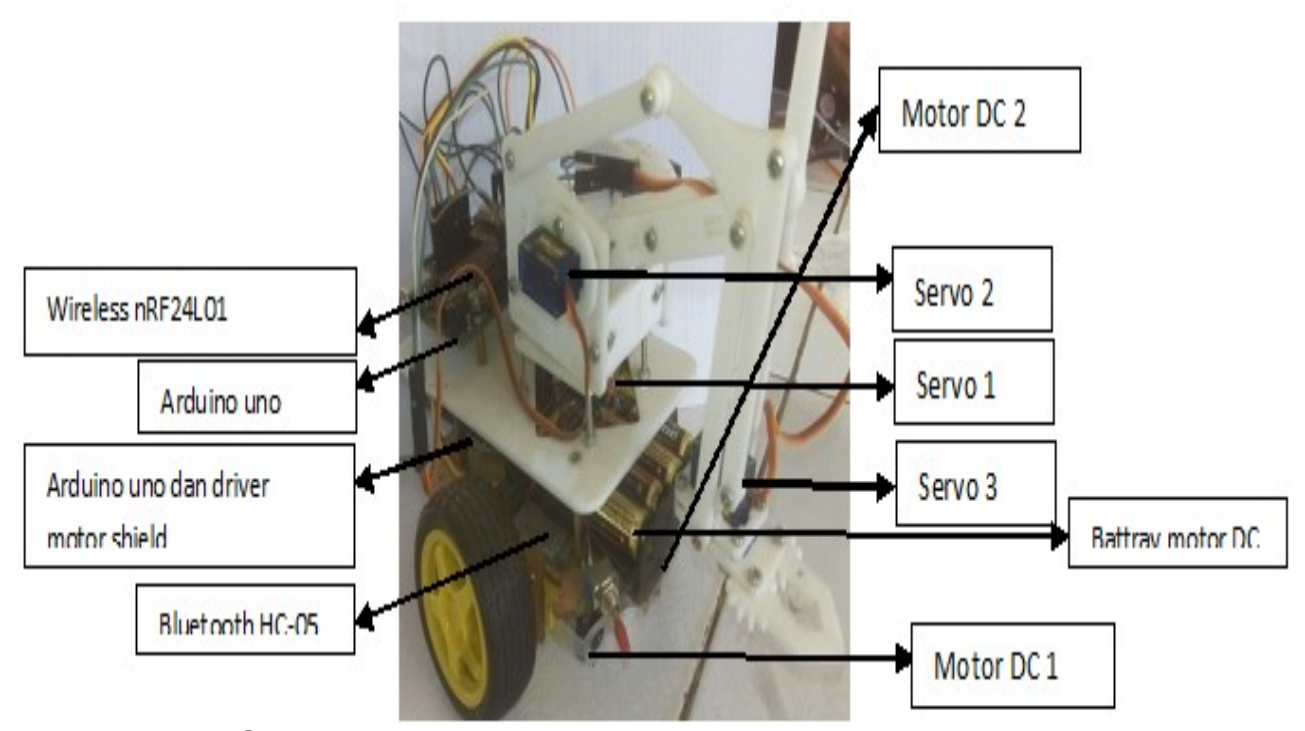

Gambar 9. Detail Robot lengan denga penggerak roda

Pada perangkat robot sinyal yang di kirimkan baik melalui Bluetooth untuk perangkat pengendali gerak yang di kendalikan menggunakan handphone android maupun melalui perangkat modul wireless NR24L01 akan diproses oleh arduino yang terdapat pada perangkat robot untuk menghasilkan output gerakan yang sesuai dengan yang diinginkan. 


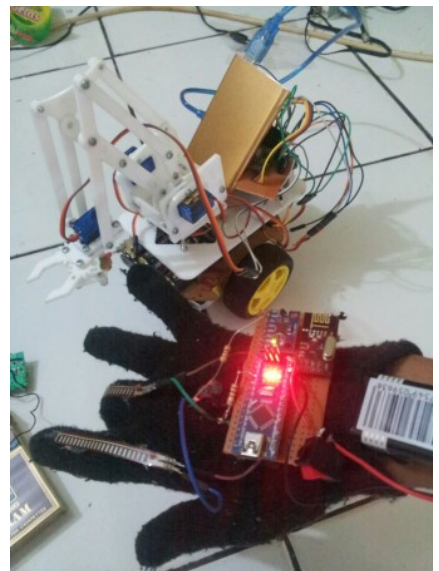

Gambar 10. Sistem keseluruhan Robot lengan

\section{Kesimpulan dan saran}

\subsection{Kesimpulan}

Dari hasil Pembahasan dapat di tarik kesimpulan bahwa pengendalian lengan robot menggunakan flex sensor dan accelerometer sensor mempermudah pengendalian dan membuat pengendalian lebih fleksibel jika dibandingkan menggunakan tombol atau menggunakan joystik.

\subsection{Saran}

Sebagai saran untuk penelitian dengan bidang dan tema yang sama yaitu untuk memperhatikan pemilihan motor servo yang di gunakan karena pada penelitian ini penggunaan motor servo yang kurang baik mengakibatkan pergerakan lengan robot menjadi sedikit terganggu sehingga pergerakan lengan robot tidak begitu alami.

\section{Daftar Pustaka}

[1] Kadir Abdul. Buku Pintar Pemrograman Arduino. Yogyakarta, Mediakom, 2014, pp. 16 - 17.

[2] Maria V, "Rancang Bangun Jari Tangan Robot Mengikuti Pergerakan Jari Tangna Manusia", Oktober 2014, SPPH-ILKOM, STMIK Global Informatika MDP, Palembang.

[3] Abdullah. "Penggunaan Sensor Keseimbangan Accelerometer dan Halangan Ultrasonic Pada Aplikasi Robot Berkaki Dua", Jurnal dan Penelitian Teknik Informatika, Vol. 1, No. 2, ISSN : 25412019, pp. 17 - 22, April 2017, Sekolah Tinggi Teknik Poliprofesi Medan, Medan.

[4] Handle Y. Jayant, Malausare Niket, Dkk, "Design for Robotic Hand Using Flex-sensor", International Journal of Advanced Research in Electronics and Communication Engineering (IJARECE), Vol 4 Issue 12, ISSN : 2278 - 909X, December 2015, India. 